\title{
Deep-Seated Giant Lipoma on the Hand Inducing Carpal Tunnel Syndrome
}

\author{
Dae-Geun Kim', Sung-II Hwang ${ }^{2}$ \\ Departments of ' Orthopedic Surgery and ${ }^{2}$ Rehabilitation Medicine, Soonchunhyang University Gumi Hospital, Soonchunhyang University College of \\ Medicine, Gumi, Korea
}

\begin{abstract}
Lipoma is a very frequent benign soft tissue tumor, but its occurrence in the hands is rare. Lipoma in the hands is generally asymptomatic; however, symptoms may develop if local neurovascular structures are compressed due to size or location of the lipoma. Carpal tunnel syndrome, which is a compressive neuropathy of the median nerve, is the most common neuropathy in the hands and presents pain, numbness, hypoesthesia, and atrophy of the thenar muscle. We present a case of carpal tunnel syndrome by deep-seated giant lipoma with a literature review.
\end{abstract}

Keywords: Wrist; Lipoma; Carpal tunnel syndrome

\section{INTRODUCTION}

Lipomas are very frequent benign soft tissue tumors derived from mature adipose tissue. They may involve every part of the body where fat tissue is present; however, the hand is not frequently involved [1]. Giant or great lipoma could be considered when lipoma is above $5 \mathrm{~cm}$ in diameter [2]. Peripheral compressive neuropathy by lipoma is uncommon. Few cases of carpal tunnel syndrome by giant lipoma in the hands were described in the literature $[3,4]$. We report a case of a 49-year-old patient with carpal tunnel syndrome due to intermuscular giant lipoma.

\section{CASE REPORT}

A 49-year-old male came to the outpatient clinic with a huge palpable mass on his left hand. The mass, which had been growing slowly for 2 years, induced pain and a tingling sensation around the second, third, and fourth fingers. On examination, the mass was large, soft, and well-circumscribed. Also, both Tinel's sign and Phalen's test were positive.

Doubting secondary carpal tunnel syndrome, we performed an electrodiagnostic examination consisting of nerve conduction study (NCS) and electromyography (EMG) in the left upper extremity nerves and muscles. The motor NCS of the left median nerve showed delayed distal motor latency, and sensory NCS of the left median nerve showed delayed latency and low amplitude at the wrist level. In addition, EMG showed that left abductor pollicis brevis muscle demonstrated normal spontaneous activity and normal motor units with a full recruitment pattern. These findings of the study suggested marked entrapment neuropathy of the left median nerve at the wrist level, which was compatible with carpal tunnel syndrome [5].

Before surgery, he had undergone a hand magnetic resonance image (MRI) with contrast. An MRI showed an isolated huge soft tissue mass measuring $4.5 \times 4.2 \times 1.6 \mathrm{~cm}$. The mass was deep-seated, intermuscular, and well-capsulated. T1-weighted images revealed a homogenous high signal intensity between the flexor digitorum tendons with contour bulging (Fig. 1A, C). Also, the lipoma showed low intensity on T2-weighted coronal and axial plane images (Fig. 1B, D). Measured cross-sectional area of the carpal tunnel at the level of pisiform was $19.2 \mathrm{~mm}^{2}$. The preoperative diagnosis would be deep-seated giant lipoma with carpal tunnel syndrome.

The patient underwent open excision of the mass and carpal tunnel release under general anesthesia. The mass was located from beneath the palmar aponeurosis to the middle portion of the hand. The gross feature of the tumor was a solitary, well-circumscribed, and capsulated mass with a smooth surface (Fig. 2A). On 

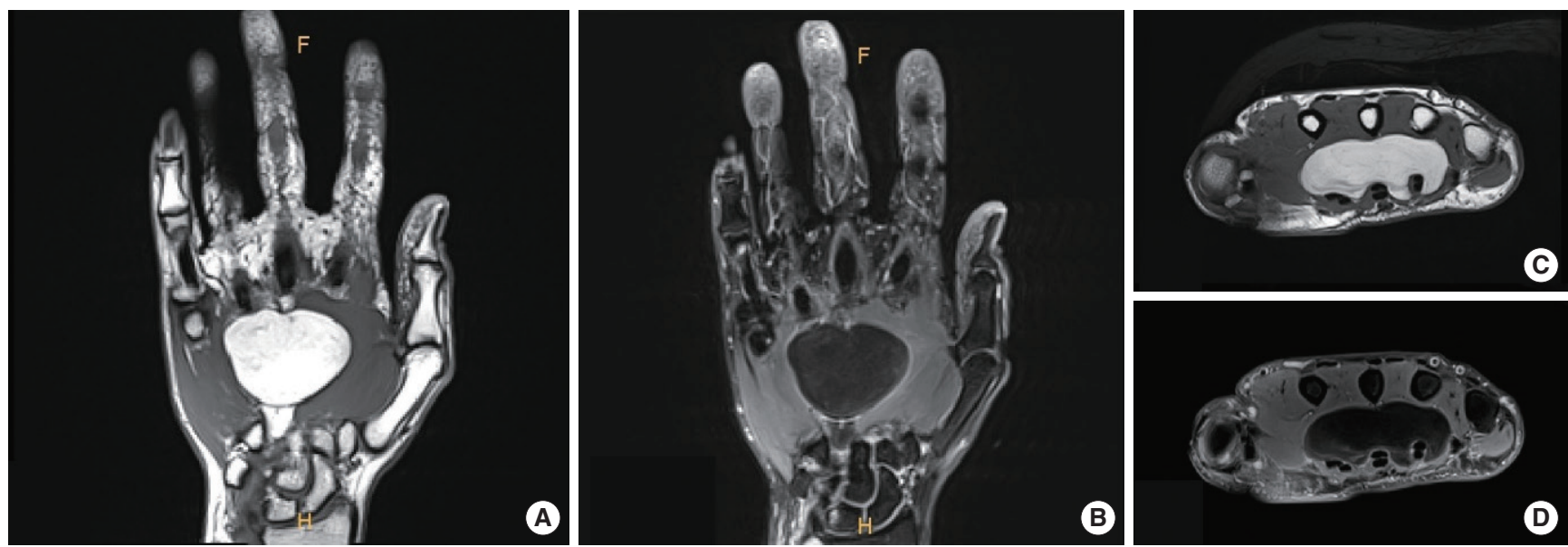

Fig. 1. Magnetic resonance imaging scans revealed that a giant lipoma which was located in the middle of the hand. The lipoma showed high intensity on T1-weighted coronal and axial plane images (A, C) and low intensity on T2-weighted coronal and axial plane images (B, D).
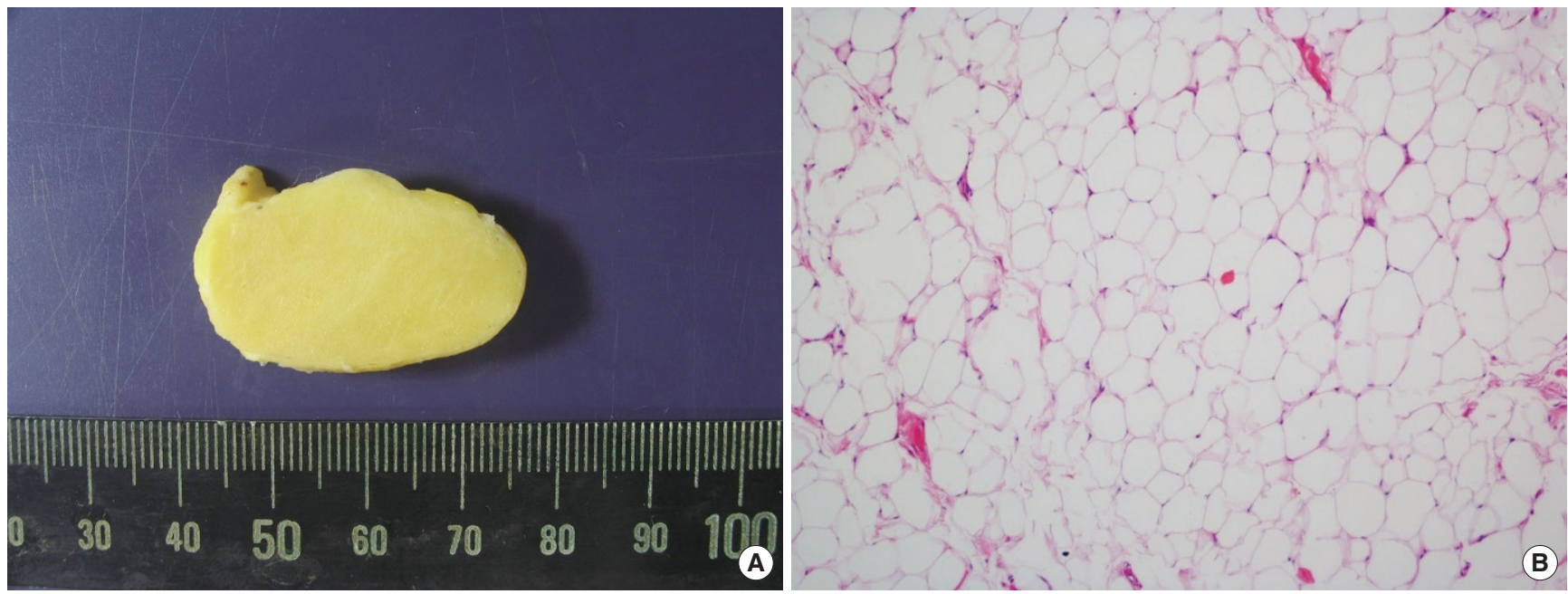

Fig. 2. The excised mass was a yellowish well-encapsulated lipoma about $35 \mathrm{~mm}$ diameter in size (A). Microscopic images showed mature benign adipocytes (H\&E, $\times 100)(B)$.

separation, it showed soft texture, yellow color with glistening stromal areas, and multiple hemorrhagic foci with central cystic degeneration (Fig. 2B). A histopathological examination confirmed the diagnosis of lipoma.

Symptoms improved gradually and finally recovered at 1 month after surgery. There was no recurrence after the 1 year of followup.

This case report has been approved by the Institutional Review Board of Soonchunhyang University Gumi Hospital (IRB approval no., SCHUH 2019-26). The patient provided written informed consent for the publication of clinical details and images.

\section{DISCUSSION}

Lipomas are the most common soft tissue tumors of mesenchymal origin. They consist of mature adipocytes and are usually encapsulated. They can occur anywhere on the body, but mostly appear on the neck, trunk, and upper extremities [6]. Lipoma in the hands is not common, and carpal tunnel syndrome due to compression of lipoma is rare $[3,6]$.

Space occupying lesions which can make carpal tunnel syndrome are distal radius fractures, carpal bone fractures or dislocation, and other soft tissue tumors such as lipoma, hemangioma, schwannoma, epidermal cyst, ganglion, and so forth [7]. Like our case, there are few cases which are giant hand lipoma induced carpal tunnel 
syndrome described in the literature. Even though conventional carpal tunnel syndrome is almost bilateral, space-occupying lesions induced carpal tunnel syndrome tends to be unilateral.

The electrodiagnostic examination should be conducted if simple carpal tunnel syndrome is doubtful. If space-occupying lesions are suspected, ultrasonography or MRI could be helpful for the identification of the lesions $[8,9]$. By using ultrasonography, we can check the size and shape of a mass. In the MRI, lipoma could be seen such as homogenous and well circumferential mass with the high-intensity signal on both T1- and T2-weighted images.

Schwannomas have fairly predictable signal characteristics which are isointense or hypointense signals on T1-weighted image, intense enhancement on gadolinium enhancement, and heterogeneously hyperintense on T2-weighted images. Epidermal cysts have traditional characteristics such as a fluid signal with variable low-signal components on T2-weight images and peripheral rim enhancement on enhanced images.

Carpal tunnel syndrome could be confirmed by measuring the cross-sectional area. According to several studies, carpal tunnel syndrome should be suspected if the cross-sectional area on a pisiform bone location is more than $10 \mathrm{~mm}^{2}$ by using ultrasonography. Park et al. [10] reported that the mean value of the cross-sectional area at the pisiform was $18.8 \mathrm{~mm}^{2}$ in the MRI of the carpal tunnel syndrome patients and the cross-sectional area of the carpal tunnel was large in the carpal tunnel syndrome patient than the normal patient. Our patient's cross-sectional area of the median nerve at the pisiform bone was $19.2 \mathrm{~mm}^{2}$ and it was larger than $18.8 \mathrm{~mm}^{2}$.

Treatment for carpal tunnel syndrome is the release of the median nerve. However, carpal tunnel syndrome due to a space-occupying lesion should be treated by a tumor excision and the median nerve release simultaneously. Before surgery, image tests such as MRI, ultrasonography must be undergone for space-occupying lesions induced by carpal tunnel syndromes.

\section{ACKNOWLEDGMENTS}

This research was supported by the Soonchunhyang University Research Fund.

\section{REFERENCES}

1. Unal M, Demirayak E, Acar B, Kose O. Simultaneous median and ulnar compression neuropathy secondary to a giant palmar lipoma: a case report and review of the literature. Cureus 2018;10:e2198.

2. Cribb GL, Cool WP, Ford DJ, Mangham DC. Giant lipomatous tumours of the hand and forearm. J Hand Surg Br 2005;30:509-12.

3. Seo KB, Kim SR, Nam KW, Choi S, Seo JY, Rho JY, et al. Carpal tunnel syndrome due to lipoma: a case report. Arch Hand Microsurg 2019;24: 197-201.

4. Ribeiro G, Salgueiro M, Andrade M, Fernandes VS. Giant palmar lipoma: an unusual cause of carpal tunnel syndrome. Rev Bras Ortop 2017;52: $612-5$.

5. Jablecki CK, Andary MT, Floeter MK, Miller RG, Quartly CA, Vennix MJ, et al. Practice parameter: electrodiagnostic studies in carpal tunnel syndrome: report of the American Association of Electrodiagnostic Medicine, American Academy of Neurology, and the American Academy of Physical Medicine and Rehabilitation. Neurology 2002;58:1589-92.

6. Rydholm A, Berg NO. Size, site and clinical incidence of lipoma: factors in the differential diagnosis of lipoma and sarcoma. Acta Orthop Scand 1983;54:929-34.

7. Kang HJ, Jung SH, Yoon HK, Hahn SB, Kim SJ. Carpal tunnel syndrome caused by space occupying lesions. Yonsei Med J 2009;50:257-61.

8. Goodwin RW, O’Donnell P, Saifuddin A. MRI appearances of common benign soft-tissue tumours. Clin Radiol 2007;62:843-53.

9. McDonagh C, Alexander M, Kane D. The role of ultrasound in the diagnosis and management of carpal tunnel syndrome: a new paradigm. Rheumatology (Oxford) 2015;54:9-19.

10. Park JS, Won HC, Oh JY, Kim DH, Hwang SC, Yoo JI. Value of cross-sectional area of median nerve by MRI in carpal tunnel syndrome. Asian J Surg 2020;43:654-9. 